\title{
Sex-Differences in Attitudes towards Mathematics of Junior Secondary School Pupils in the Central Region of Ghana
}

\author{
Asare-Nkoom, S
}

\begin{abstract}
The study investigated junior secondary school pupils' attitudes towards mathematics. In addition, it investigated gender differences in attitudes towards the subject. The purposive sampling method was used to select nine schools in the Cape Coast Municipality, involving 581 pupils. Questionnaires on attitudes towards mathematics were used to gather data. The data was analyzed using the computer. The analysis involved calculating means, and finding significant differences in means of specific respondents by the Kruskal-Wallis test. The results of these analyses showed that both boys and girls at the JSS level had positive attitudes towards mathematics in all eight attitude dimensions. Both sexes did not see mathematics as a male dominated domain, with girls seeing it less a male domain than boys.
\end{abstract}

\section{Introduction}

Mathematics is a subject found in every school curriculum. In Ghana, all pupils in basic and senior secondary schools must study the subject. Despite this, the learning of the subject is still not satisfactory. Anamuah-Mensah, Mereku, and Asabere-Ameyaw (2004) reported that over $80 \%$ of the students in Ghana did not reach the low international benchmark in mathematics, implying that the majority of Ghanaian students have no good grasp of knowledge and conceptual understanding of basic mathematical principles. Although there was no significant difference in the performance of boys and girls in mathematics in the 'Trends in International Mathematics and Science Study' (TIMSS-2003) reported by Anamuah-Mensah, et al. (2004), it is differences were observed between boys and girls in their attitude to the subject and aspirations for higher education. Frempong and Ayia (2006) also found that female students are less successful in learning mathematics. They attributed this to their low interest and confidence in learning mathematics and their low academic expectation.

Earlier, Eshun $(1999,2000)$ found that in Ghana girls in mixed schools expressed the least success and confidence in doing mathematics and have higher mathematics anxiety. This is consistent with findings of AAUW (1992) that girls' self-esteem, confidence in their abilities, expectations for life, interest in challenging courses and rewarding careers, and pursuits in mathematics and science decline as they get older. Eshun (1999) also reported that in general, students had positive attitudes towards mathematics especially along the attitudinal variables, usefulness of mathematics, like doing mathematics, and experience of success in mathematics. Eshun and Abledu (2001) revealed that students are however least positive about effective motivation, and confidence in doing mathematics. They concluded that students' low achievement in mathematics could partly be attributed to lack of motivation and confidence to learn the subject.

Initially girls have positive attitudes towards mathematics than boys do, but as they continue in school, girls' attitudes become more negative. This is supported by Swetman (1995) who observed that girls' positive attitudes towards mathematics decline as they grow older. Girls' attitudes towards mathematics may be linked to their opinions of the relevance of the subject. Lamb (1997) reported that girls agreed less often with the view that mathematics was as important as other subjects to their future careers ( $61 \%$ as against $73 \%$ of boys). Such a view definitely affects their efforts to achieve in the subject. Thus, hindering the achievement rates of the girls as against the boys. Anamuah-Mensah et al (2004) also found high self-confidence in mathematics to be associated with better performance in the subject.

If females do not see mathematics-related careers as possibilities, they might also not see mathematics as useful. In Ghana, Anamuah-Mensah et al (2004) report that students with higher 
aspirations performed better in mathematics and science than those who did not have such aspirations. Eshun (2000) pointed out that "usefulness" is an affective variable which helps to explain that a female not electing mathematics is due to the perceived usefulness of the subject to her. To the females, mathematics is a difficult subject and not particularly enjoyable, so they do not see any need to study it. Eshun $(1999,2000)$ goes further to state that as a group, females in secondary schools indicate they do not feel they will need or use mathematics in the future, but males as a group is apt to report that mathematics is essential for whatever career they plan. These sex differences on perceived usefulness are also related to the stereotyping of mathematics as male domain. Girls' confidence in their mathematics ability tends to match that of boys in the primary school years and deteriorates more rapidly during high school (Brush, 1990; Heller and Parsons, 1981). Thus, during their schooling, girls develop a lower estimation of their own abilities in mathematics than do boys. This impression is usually influenced by some teachers and parents.

Naturally, one tends to do things that one has confidence in, and avoids those things which one thinks may arouse anxiety. Tobias and Weissbrod (1980) cited anxiety as a strong factor for girls to avoid mathematics and mathematics related courses, as they tend to suffer more from "Mathematics Anxiety" than boys. This anxiety has been described by them as a kind of panic or helplessness that develops when a mathematics problem is presented. A classroom characterized by heightened anxiety is seen as threatening, bewildering and leading to guilt, embarrassment or shame (Buxton, 1981, 1982). Eshun (2000) reported that high anxiety is associated with lower achievement in mathematics and also that there is a positive relationship between self-esteem and mathematics achievement. He also reported that girls trained in single-sex environment demonstrate lower level of fear of success in any field of endeavour. He likened this feeling to the fact that girls in single-sex schools operate within their abilities and capabilities. They thus experience success among their peers.

Perceptions of boys and girls may also account for their attitude variations. Middle school students do not recognize the subjects that they must study in order to have specific careers. In a survey of 162 students about their career aspirations and their feelings about sex stereotypes in certain professional fields, students responded that society accepts many different careers for women and men (Petitt, 1995). However, they tended to choose sex-stereotyped careers when filling out the survey. Girls felt that they would be capable of becoming doctors or veterinarians, but they did not want to have science-related careers as adults. Boys stated the opposite. Neither the boys nor the girls recognized the relation between the study of mathematics and science and their future career aspirations

All the review shows that male superiority is evident at the upper elementary or junior secondary school level and in addition, males are superior in high-level cognitive tasks, which increases its importance as one advances higher in mathematics study. Schwartz and Hanson (1992) however report that teachers must consider girls' mental and physical development and the effect of their own attitudes and behaviors on girls' participation and performance in mathematics. When girls begin to physically mature, they focus more on their bodies and less on their intellectual abilities or themselves as people. As a result, their self-esteem decreases. Eshun (2000) found that a positive relationship existed between academic achievement and self-esteem; and that girls' learning style is more cooperatively based and therefore does not mesh with the independent, noncollaborative thinking encouraged in most classrooms. From the discussions above, there appears to be a varying degree of attitudes toward mathematics among pupils at the junior secondary level, and also gender differences in attitudes toward the subject.

\section{Research Questions}

The study sought to investigate Junior Secondary School (JSS) pupils' attitudes towards mathematics and determine any gender-differences. The following questions were therefore formulated for the study:

1. What attitudes do Ghanaian JSS pupils have towards mathematics?

2. Are there any gender-differences in attitudes of JSS pupils towards mathematics in Ghana? 


\section{Methodology}

\section{Population and Sample}

The targeted population for the study comprised all Junior Secondary School (JSS) pupils in the Central Region of Ghana. The sample was taken from the final year group of the Junior Secondary Schools. The sample comprised five hundred and eighty-one (581) pupils from nine schools of the Cape Coast Municipality. Of these, one was a boarding JSS, two were private JSS, and the rest either of single-sex male, single-sex female or mixed and public type. The breakdown is shown in Table 1.

\section{Table 1 Distribution of pupils by type of school}

\begin{tabular}{ll}
\hline Type & Number \\
\hline Single-sex male & 61 \\
Single-sex female & 158 \\
Mixed male & 172 \\
Mixed female & 190 \\
Total & 581 \\
\hline
\end{tabular}

The targeted schools were visited and the Headmasters (J)/Headmistresses (J) served with copies of a letter seeking permission to conduct the study. The heads were notified of the intended period when the study would be conducted and asked to specify a convenient day on which they could make their pupils available for the study involving a questionnaire. They were also informed to notify their JSS3 mathematics teachers to get the selected pupils ready for the study. The time of the study coincided with the period of the pupils' intensive preparations for their final BECE Examinations. It was therefore hoped that pupils have had adequate interactions with the subject mathematics.

The selection procedure described above was used to suit the descriptive survey type of study chosen. As pointed out by Gay (1987), this design involves collecting data in order to test hypotheses or to answer questions concerning the current status of the subject of study. Johnson (1988) stated that this type of study provides a descriptive picture of a situation to establish norms and baseline data for consideration by research practitioners in making their decisions to help raise relevant questions, or identify needed research. The procedures are expected to help determine and report the way things are. That is, provide a true record of students, especially JSS students' attitudes towards mathematics in the Central Region of Ghana.

\section{Research instrument}

The Likert scale was followed in preparing the questionnaire used in the study. This scale is based on statements that are classified as positive or negative. Each statement has five options of which one is selected according to the respondent's feelings. Weights of 1, 2, 3, 4 and 5 were attached to the options of "Strongly Disagree (SD)", "Disagree (D)", "Undecided (U)", "Agree (A)", and "Strongly Agree (SA)" respectively when the statement is positive. This was reversed for a negative statement. For instance, to a positive statement, "one can use mathematics in daily life", if a response is SA, it received a weight of five. However, to a negative statement, "it is useless for females to learn mathematics", if a response is SA, it received a weight of one. A neutral response of "Undecided (U)" to each item gained a mean weight of three.

A mean score above three was taken to indicate a positive attitude whilst a mean score below three suggested a negative attitude. Subjects were made to respond to the fifty-nine items comprising, ten items on the respondent's background, and forty-nine items on respondent's attitude towards mathematics of the questionnaire's close-ended items. Subjects were to provide a tick or write down the most appropriate initials of the pre-printed responses of each item. 
Eight attitudinal variables, each regarded as a dimension along which a score reflected a positive or negative attitude of a student were tested for the study. The attitudinal variables and typical items can be seen in Table 2 .

Table 2 Attitude Variables and Typical Items

\begin{tabular}{cl}
\hline \multicolumn{1}{l}{ Item } & Variable \\
\hline 11 & Usefulness of mathematics \\
24 & Confidence in mathematics \\
46 & Experience of success in mathematics \\
12 & Effective motivation for mathematics \\
14 & Mathematics Anxiety \\
15 & Mathematics considered as a male domain \\
31 & Understanding mathematics \\
39 & Like solving mathematics problems \\
\hline
\end{tabular}

Statements that correspond to the attitude variables stated in Table 2 are as follows: 11 . Mathematics is the most useful subject of all. 24. I like mathematics because you can figure things out instead of memorizing. 46. I do not think mathematics is fun but I always do well in it. 12. Studying mathematics gives me enormous pleasure. 14. I am always under a terrible pressure in mathematics class. 15. Boys need mathematics more than girls. 31. It takes me too much time to understand any idea in mathematics. 39. Mathematics thrills me, and I like it better than any other subject.

The questionnaire items were hand delivered to respondents on the days that were agreed upon by the heads of the schools. The mathematics teachers assisted in the administration of the questionnaires. The completed items were collected soon after pupils finished responding to them.

\section{Data Analysis}

As stated earlier, eight main groups of independent dimensions or variables were classified from the questionnaire items. Each dimension consisted of a collection of the various items into a unit that pointed to specific aspects of attitude towards mathematics. For instance, "I am always under a terrible pressure in mathematics class" suggests a feeling of mathematics anxiety. For an increased internal consistency of the questionnaire, a mixture of positive and negative statements was included. Table 3 shows a classification of the questionnaire items into units.

Table 3 Questionnaire items contributing to the various dimensions by nature of statement

\begin{tabular}{lll}
\hline \multirow{2}{*}{ Attitude Variable } & \multicolumn{2}{c}{ Nature of Statement } \\
\cline { 2 - 3 } & \multicolumn{1}{c}{ Positive } & \multicolumn{1}{c}{ Negative } \\
\hline Usefulness of Mathematics & $11,19,22,30,32$ \\
Confidence in doing mathematics & 24 & $26,29,34,36,37$ \\
Experience of success in mathematics & 44,46 & 25,34 \\
Effective Motivation & 12,45 & 23,48 \\
Mathematics Anxiety & $15,21,28,36,46$ & $21,30 \mathrm{a}$ \\
Mathematics as a Male domain & $17,31 \mathrm{a}, 35,38,41,43$ & 20 \\
Understanding Mathematics & & $14,31,49$ \\
Like solving Mathematics Problems & $19,27,38,39,40$ & $28,29,32$ \\
\hline
\end{tabular}

Under each dimension, the mean of the weights attached to each item were found. This was recorded by type of school and sex for the attitudinal variables. Kruskal-Wallis analysis of variance was used to compute and test whether there were any significant differences in mean responses of:

i. $\quad$ girls in single-sex schools and boys in mixed schools 
ii. girls in single-sex schools and girls in mixed schools

iii. girls in single-sex schools and boys in single-sex schools

iv. boys in mixed schools and girls in mixed schools

v. boys in mixed schools and girls in both mixed and single-sex schools.

\section{Results}

About two-fifths, representing $40 \%$ of respondents were boys whilst three-fifths, representing $60 \%$ of respondents were girls. Of the boys, there were more boys in mixed schools than boys in singlesex schools. This was intended to find out if the presence of girls would have any effect on the boys. Of the girls, there were more girls in mixed schools than girls in single-sex schools. The average age of respondents was found to be 15.0 years. Only one pupil was ten years old whilst 19 pupils were aged 18. The highest number of respondents was for the age of 15 years. This implies that much as there were a few respondents with ages falling outside the expected age range of 14 to 16 , the majority fell within the range. Of those wishing to proceed to the senior secondary school (SSS), 95.4\% responded in the affirmative. Thus almost all respondents would like to proceed to secondary school. Table 4 shows the means of scores on the eight attitude dimensions by type of school and sex.

Table 4 Means of Attitude Scores by Type of School and Sex

\begin{tabular}{lccccc}
\hline Attitude Variable & $\begin{array}{c}\text { Single-sex } \\
\text { (male) }\end{array}$ & $\begin{array}{c}\text { Single-sex } \\
\text { (female) }\end{array}$ & $\begin{array}{c}\text { Mixed } \\
\text { (male) }\end{array}$ & $\begin{array}{c}\text { Mixed } \\
\text { (female) }\end{array}$ & ALL \\
\hline Usefulness & 3.67 & 3.81 & 3.78 & 3.87 & 3.77 \\
Confidence & 2.99 & 3.05 & 2.97 & 3.02 & 3.01 \\
Success & 3.24 & 3.43 & 3.41 & 3.39 & 3.37 \\
Motivation & 3.02 & 2.98 & 3.04 & 3.03 & 3.02 \\
Anxiety & 2.80 & 2.91 & 2.91 & 3.05 & 2.92 \\
Male domain & 2.83 & 2.36 & 2.56 & 2.40 & 2.54 \\
Understanding & 3.68 & 2.98 & 3.16 & 3.22 & 3.26 \\
Like Maths. & 3.45 & 3.53 & 3.29 & 3.41 & 3.42 \\
\hline
\end{tabular}

Table 4 shows that the mean scores for all students in the sample were above three, for six out of the eight attitude variables. This is an indication that the students selected more positive items of the attitude dimensions. The most positive responses were for usefulness of mathematics, like solving mathematics problems, and experience of success in doing mathematics, in that order. The table shows that students in mixed schools had more positive responses on attitudes towards mathematics in all eight dimensions than students in single-sex schools. None of the sexes regarded mathematics as a male domain, but females saw mathematics as less a male domain than males. Females in mixed schools had more mathematics anxiety, whilst students in single-sex schools showed less mathematics anxiety. Students were undecided about their confidence in learning mathematics.

\section{Discussions}

In testing whether there was any difference in attitudes of JSS boys and girls towards mathematics, it was found that there was no significant difference in attitudes towards mathematics of boys and girls at the JSS level. This is an indication that students of both sexes have the same feelings towards mathematics. The finding that both sexes of students showed the same feelings towards mathematics is corroborated by Brush (1990) that girls' confidence in their ability tends to match that of boys in the primary years. These findings might have come about as a result of differences in learning environments, and teacher or parental perceptions of the pupils. 
Boys and girls agreed that mathematics was as important as other subjects. This finding also contradicts findings by Lamb (1997) as stated in the literature above. There is the likelihood therefore that both sexes would express similar feelings towards the subject. It was found that though both sexes expressed enjoyment in studying mathematics, girls in single-sex schools showed more that they enjoyed studying the subject than boys and girls in mixed schools, and boys in single-sex schools. This is an indication that such environments provide girls with freer feelings to discuss their needs. They also tend to show more sympathy for one another. This implies that a single-sex environment is more academically friendly for female students and they would learn any thing taught them under such an environment.

Girls expressed more confidence in learning mathematics than boys. Girls in single-sex schools expressed more confidence in learning mathematics than girls in mixed schools. Boys in singlesex schools also expressed more confidence in learning mathematics than boys in mixed schools. Thus, students in single-sex schools showed more confidence in learning mathematics than those in mixed schools. An implication to the higher confidence by students in single-sex schools could be teachers' interest in these groups than the mixed. Children's attitudes were influenced more by parents' and teachers' attitudes than by their own past performances.

\section{Conclusions}

The findings have shown that boys and girls in JSS had positive attitudes towards mathematics. Furthermore, both sexes saw mathematics as a useful subject but girls rated it as more useful to them than boys. However, variables such as mathematics anxiety, difficulty of mathematics and stereotyping of mathematics as a male domain were cited in the literature as preventing females from opting to study elective mathematics at the SSS. Tobias and Weissbrod (1980) for instance, cited mathematics anxiety as a strong factor deterring girls from taking mathematics and mathematics related courses because they tend to suffer more mathematics anxiety than do boys. This study however found both boys and girls not to have mathematics anxiety. In addition, girls more often than boys did not see mathematics as a difficult subject to study. Furthermore, more girls than boys did not see mathematics as a male domain. These could be as a result of the perceptions of their teachers as reported by Schwartz and Hanson (1992) that the attitudes and behaviors of teachers on girls' participation affect their performance and attitude in mathematics. In effect, the three variables, mathematics anxiety, mathematics as a male domain, and mathematics as a difficult subject cited in literature as major variables deterring females from studying mathematics seemed not to be applicable to males and females in this study.

\section{References}

AAUW - American Association of University Women (1992). 'Short-changing Girls, Shortchanging America: A call to Action'. Initiative for the Educational Equity, Washington, DC: American Association of University Women

Anamuah-Mensah, J., Mereku, D. K. and Asabere-Ameyaw, A. (2004). Ghanaian Junior Secondary School Students' Achievement in Mathematics and Science: Results from Ghana's participation in the 2003 Trends in International Mathematics and Science Study, Accra: Ministry of Education Youth and Sports.

Becker, J. R (1981). Differential treatment of females and males in mathematics classes. Journal for Research in Mathematics, 12, 40-53.

Brush, G (1980). Encouraging Girls in Mathematics: the problem and the solution. Cambridge: MA, ABT Associates.

Buxton, T (1981) The contextual nature of teaching: Mathematics and reading instruction in one second-grade classroom. Elementary School Journal, 90 (5) 497-514.

Eshun, B. A (1999). Pattern of Mathematical Achievement of Secondary School Students in Ghana. Journal of Science and Mathematics Education, 2(1).22-33. 
Eshun, B. A. (2000) 'Sex-Differences in Attitude of Students Towards Mathematics in Secondary Schools'. Journal of the Mathematical Association of Ghana. Vol. 13. pp. 1-14.

Eshun, B. A. and Abledu, G. K. (2001). The Effect of Alternative Assessment on the Attitudes and Achievement in Mathematics of Female Pre-Service Teachers in Ghana. African Journal of Educational Studies in Mathematics and Science, Vol. 1. pp. 21-30

Frempong, G. \& Ayia, J.K. (2005). Equity and Quality Mathematics Education Within Schools: Findings from TIMSS Data for Ghana'. Proceedings of the 31st Annual IAEA Conference of International Association for Educational Assessment (IAEA)

http://www.iaea.info/index.php?option=com_conferences\&task=showAbstract\&id=49\&It emid $=45$

Heller, K. \& Parsons, J (1981). Sex differences in teachers' evaluation feedback and students' experiences for success in mathematics, Child Development, 52, 1015-1019.

Lamb, S (1997). Gender Differences in Mathematics Participation: An Australian perspective. Educational Studies, 23(1). 105-125.

Petitt, L (1995). "Middle School Students' Perception of Math and Science Abilities and Related Careers", Proceedings of the $61^{\text {st }}$ Biennial meeting of the Society for Research in Child Development, Indianopolis, IN.

Schwartz, W and Hanson, K, (1992). "Equal Mathematics Education for Female Students". Educational Development Center, Inc., Newton, MA: Center for Equity and Cultural Diversity.

Swetman, D. (1995). "Rural Elementary Students' Attitudes toward Mathematics", Rural Educator, 16(30). 20-22, 31

Tobias, S. \& Weissbrod, C. (1980). Anxiety and mathematics: AN update. Harvard Educational Review, 50, 63-70. 